\title{
Petrographic Microscope Digital Image Processing Technique for Texture and Microstructure Interpretation of Earth Materials
}

\author{
Beatriz M. Dias ${ }^{1}$, Victor F. Velázquez ${ }^{1}$, Rodrigo F. Lucena ${ }^{1} \&$ José M. Azevedo Sobrinho $^{2}$ \\ ${ }^{1}$ School of Arts, Sciences and Humanities, University of São Paulo, Brazil \\ ${ }^{2}$ Geological Institute, São Paulo Environmental System, Brazil \\ Correspondence: Victor F. Velázquez, School of Arts, Science and Humanities, University of São Paulo, Brazil, Rua \\ Arlindo Béttio, 1000 - Vila Guaraciaba, São Paulo - Brazil. E-mail: vvf@usp.br
}

Received: November 14, 2019

doi:10.5539/esr.v9n1p58
Accepted: January 17, 2019

Online Published: January 30, 2020

\begin{abstract}
The technique of description and characterization of rocks with the aid of a polarized light microscope is a well-established practice in the fields of mineralogy and petrology. However, because geological materials are inherently highly variable on a small scale, capturing good-quality images, particularly of the fine details present in the mineral grains that compose the rock, is the main difficulty encountered when a thin section is examined under a petrographic microscope. Combining petrographic concepts and digital image processing methods, the principal aim of this paper is to provide a practical approach to digital image treatment with specific software, and its immediate application in the micromorphological characterization of minerals. In addition to the basic calibration of color, brightness, and contrast, three different methods of digital image processing in the spatial domain, following the principles of embossed surface, negative image, and edge detection techniques, were applied to the images. The use of these primary filters was found to be efficient for detailed characterization of the mineralogical phases involved in the different types of microstructures. However, special care must be taken regarding the sensitivity and accuracy parameters to avoid the exclusion of information or the addition of noise to the image. Although research has focused on the distinction of several types of textural features in rock-forming minerals, these techniques can be employed in other areas of investigation, in both academic and industrial settings, to diagnose textures of microtectonic deformation, soil micromorphological features, the proportions of the original ingredients in concretes, and the mineralogical modal determination of ceramics of archeological origin and to characterize mineral raw materials for the manufacture of technological products.
\end{abstract}

Keywords: digital image, processing technique, texture and microstructure, earth materials

\section{Introduction}

In 1848, there was a considerable advance in the study of rocks and minerals when Henry Clifton Sorby employed the technique of microscopic petrography. For the first time, Sorby examined a sample of rock in thin section under a microscope using polarized light (Nuttall, 1981). Seventeen decades later, the polarized light microscope, or petrographic microscope, is still the most widely used instrument to perform detailed descriptions of rock in thin section preparation (Gribble \& Hall, 1992). In addition to its broad application in the geological sciences, this technique is similarly used in several other areas, such as forensic medicine and environmental, textile, soil, and archeological sciences (Stoiber \& Stearns, 1994).

Of the various professionals, geologists are among those that most directly benefit from the visual data in images. Usage of such data can range from simple cartographic representations of surface lithological units (Spencer, 2018) to subsurface seismic profiles (Onajite, 2014) and microscopic images of the optical features of small mineral grains (Broche, Casanova \& Loup, 1977). However, when using numeric image data, the scenario is quite different, and the reality seems to follow at least two tendencies. On the one hand, the vast majority of relevant software has been designed to quantify the sizes and shapes of particles and quickly gained a large number of users, mainly among professionals seeking to better understand the close relationship between the porosity and permeability of rocky substrates (Berryman \& Blais, 1986). On the other hand, some with malicious intent have incorrectly argued that a digital image can only provide visual information.

According to Chaki, Shaikh and Saeed (2014), a digital image is a dense matrix of measures of any property of an object, and its main advantage lies in the possibility of rearranging that coded matrix to highlight elements of interest. 
For those more familiar with the subject, it may seem natural that a digital image is a set of binary-coded numbers that can be easily manipulated on a computer using appropriate software. However, it is important to remember that even for experts in the field, the immediate application of image processing techniques in the different branches of science is not always an axiomatic situation, and in this regard, unfortunately, there is considerable progress to be made. A means to change this scenario is that researchers, in their respective areas of expertise, accurately assess encountered problems to establish the most appropriate techniques to meet their needs.

For centuries, maps containing visual information were the only primary data source for geologists to represent geological processes that shape the Earth's surface (Barnes \& Lisle, 2004). With the emergence of digital images and powerful processing programs, the photographic record has become a much more accurate graphical document and, in many cases, the only alternative to reveal the traces of a geological event that occurred on a microscopic scale. Currently, there is a wide variety of high-resolution digital cameras, petrographic microscopes, and high-performance computers that allow the collection, storage, analysis, and processing of images according to the demands and needs of each researcher (Pakhira, 2011). This is the main motivation for work documenting the use of digital images and treatment techniques with specific software, and their immediate application in the micromorphological characterization of minerals.

\section{Methodology and Materials}

\subsection{Petrographic Thin Section Preparation}

In photomicrography, several factors may be decisive in obtaining a good-quality digital image, and the first that should be considered is preparing the petrographic thin section. Nonopaque grains with thicknesses less than $20 \mu \mathrm{m}$ and greater than $50 \mu \mathrm{m}$ may display different optical properties, and the mineral being observed may present considerable changes with respect to the index of refraction, pleochroism, and birefringence (Mange \& Maurer, 1992). Thus, the ideal thickness for determining the optical characteristics of a mineral is $30 \mu \mathrm{m}$. To satisfy this requirement, the thin sections used in this study were prepared from 100 samples of igneous and metamorphic rocks at Actlabs Laboratories Ltd., Ancaster, Canada, following the laboratory's routine of quality control. Fifty thin sections were carefully chosen from this collection to capture the images.

\subsection{Petrographic Microscope and Digital Camera System}

The images were taken using a trinocular microscope with a coupled digital camera, models BX51 and E-40, both manufactured by Olympus Corporation. The Olympus BX51 optical microscope is equipped with a 10× magnification eyepiece, four objective lenses $(4 \times / 0.13,10 \times / 0.30,20 \times / 0.50$, and $40 \times / 0.75)$, and a bright halogen light source, which allow a wide and clear viewfield. The Olympus E-40 digital camera, with an RGB color filter array, 10 million effective pixels, and a maximum image size of 3,648 $\times 2,736$ pixels, performs fairly efficiently. With this quality standard, the captured images offer greater possibilities of enlargement and cropping, should those be necessary, without compromising the quality of the information contained therein.

\subsection{Acquisition and Processing of Images}

Although a large proportion of modern petrographic microscopes now come with digital image capture systems for a great variety of types of analysis, access to this kind of equipment is still quite limited because of its high commercial value. Fortunately, a large number of software applications are available that examine an image in 2D, sort objects, perform interactive measurements, enhance images, and use morphological filters to precisely segment structures. Therefore, each user may find alternative software that best fits his or her needs. We have used some of the packages that are available commercially and others with open licenses that can be downloaded from various websites. After performing several tests, and because each type of problem requires a different approach, we adopted the following software to conduct this research: Affinity Photo, ImageJ, Levenhuk ToupView, Image Analyzer, and PhotoScape. These programs support the most commonly used image file formats (JPEG, GIF, BMP, TIFF, and PNG, among others) and offer specific modules and tools for the greatest variety of functions, such as focus stacking, surface plots, line profiles, lens profile correction, resizing and cropping, color mapping, and several other applications to improve image quality.

It is important to remember that, regardless of the software used for digital processing, digital images represent continuous natural scenes, and it is essential that the image capture complies with a few basic conditions: i) the framing and the position should ensure maximum illumination of the mineral; ii) the focusing procedure must be performed correctly. Obtaining an enlarged image of extremely small objects requires additional care. In this case, it is wise to focus on parallel nicols and adopt the thinner trace of the mineral as a reference; iii) initial calibration of image adjustment, color balance, saturation, brightness, and contrast should be performed; iv) the image should always be captured with the highest resolution of the camera to ensure sufficient quantity of information for the desired level of 
detail.

In broader terms, image enhancement processes consist of using computation techniques to improve the visual appearance of an image and thus obtain a better visual field to examine the features of major interest (Pratt, 2007). From this point of view, it should be noted that there is no specific protocol to follow in the application of image enhancement tools. The adjustments to be incorporated into the image depend exclusively on the type of information that the user wants to take advantage in the image. For this reason, it was considered opportune to provide basic procedure criteria to standardize the techniques that have been shown to be useful for improving image quality. However, this study was not intended to provide a detailed review of the matter because several textbooks exist with topics specific to each issue.

\subsubsection{Elementary Image Manipulation}

\subsubsection{Contrast Stretching}

The contrast has a significant visual impact on low-relief index minerals, creating deeper shadows and more pronounced highlights in the surface relief. A scene that has little difference between light (light pixel values) and obscure (dark pixel values) areas inevitably gives rise to a low-contrast image. Redistributing the full range of pixel values allows regions of lower local contrast to gain higher contrast. To obtain this result, it is necessary to examine the limits of pixel values in the original image and correctly select the new parameters to be inserted into standardize the image.

\subsubsection{Brightness Level Adjustment}

Unlike light from a natural environment that vibrates in any direction, all light passing through a petrographic microscope is induced to vibrate in only one plane, usually in the W-E direction. In practice, the brightness of an anisotropic mineral is directly related to the crystallographic orientation, and under this condition, the image should be captured at the position of maximum illumination of the mineral grain. A color digital image is a combination of the three primary colors of light: red, green, and blue. Thus, the brightness of a color image is represented by the variation of the minimum and maximum intensities of each primary color (Petru \& Bosdogianni, 1999). A brightness correction tool should be run in conjunction with contrast stretching, as with brightness adjustment, the bright areas of the image will be even more brilliant. High output settings are not recommended because they may result in loss of image detail.

\subsubsection{Color Balance}

All anisotropic minerals, when observed under polarized light, exhibit variations in color tonality, called interference color. This property depends directly on birefringence, which is the difference between the extreme principal refractive indices of the mineral grain (Fleischer, Wilcos \& Matzko, 1934). This optical phenomenon is very useful for the identification of a mineral; therefore, adjusting the color level of a grain should be done with the utmost care so as not to falsely represent the color of the mineral. The most popular image editing software provides tools that operate essentially on the red, green, and blue channels. Although the changes are usually not drastic, it is highly recommended that, during color correction, the original illumination with which the image was acquired be preserved.

\subsubsection{Basic Image Transformation}

\subsubsection{Embossed Surface}

The embossed surface technique simply intensifies the contrast of an object's contours to cause a depth effect and achieve better definition between the object and the surrounding environment. Although there are several types of enhancement filters, two are of particular importance to simulate a relief appearance in an image: Laplacian-type and directional difference filters (Umbaugh, 2018). Both methods provide excellent results, but difference filters, depending on the selected filter convolution masks, allow details to be enhanced in four different directions. This technique is very efficient to perform analysis and characterization of interlocking textures.

\subsubsection{Image Negative}

Professionals of the area of image edition know that some details require less effort to be seen in negative images than in positive images. Because of the type of processing, the negative of an analog image is commonly observed on a transparent plastic film, where the natural colors of the object are inverted; light elements appear dark, and the obscures are clear within the image (Russ, 2011). In essence, the final result of the color balance inversion is not very different for a digital image, and similar effects can be obtained through manipulation tools, reversing the pixel values of the positive image. This transformation is particularly useful for viewing the discontinuities of cleavage, twinning, displacement of microfractures, and areas of different crystallographic orientation within a single mineral grain.

\subsubsection{Edge Detection}

The most frequently used procedure in digital image processing is edge detection. It is a useful tool to precisely trace 
the shape, size, and continuity of all or part of an object. In most cases, the quality of the result depends on the contrast of the object's brightness variation rate in the image (Umbaugh, 2018). A comprehensive analytical approach and specific techniques of alternative procedures concerning edge detection are described by Hagara and Kubinec (2018). The precise determination of the edge boundaries of a poikilitic texture, symplectic intergrowth, and overgrowth lines can be crucial for more accurate assessment of the nucleation and growth rates of some minerals.

\section{Image Processing for Texture and Microstructure Characterization}

Far beyond the petrological importance of geochemical and isotopic data, accurate interpretation of the conditions under which texture and microstructure were generated is essential for understanding the origins and evolution of minerals and rocks (Winter, 2014; Vernon, 2018). When a mineral is examined from a petrographic thin section, regardless of the microscope's resolution capability, there are frequently situations in which greater optical magnification, without distorting the morphological aspect of the texture under analysis, is required to perform a more detailed evaluation of the mineralogical features. From this point of view, image processing is a powerful tool not only to improve the visual perception of the object but also to highlight elements of interest in the image. It is important to emphasize that the techniques used for each of these tasks are not always the same, and to give greater visibility to the results obtained, it was considered convenient to group the minerals according to their optical birefringence. Therefore, the following presents a set of techniques that have been shown to be advantageous for solving problems in different situations.

\subsection{Low Birefringence Minerals}

Based on this optical property, some of the most relevant features documented in quartz and plagioclase feldspar are described. In addition to low birefringence, a common optical characteristic between these minerals is low relief. The contour that delimits each grain is usually difficult to establish accurately (Figure 1). This problem is well illustrated in the microstructure present in quartz grains that comes from a dynamo-thermal metamorphic process, where it is possible to notice, with some difficulty, that the crystals were subjected to intense deformation, characterized by undulating extinction, sinuous contacts between the grains, formation of subgrains, and grain boundary migration. A similar example concerns the additional effort needed to identify the delicate intergrowth between quartz and plagioclase feldspar minerals, known as myrmekitic intergrowth (MacKenzie, Donaldson \& Guilford, 1982). Comparable in some ways to the two previous cases, plagioclase feldspar grains can also present intensely deformed polysynthetic twinning, in which the presence of continuous narrow bands of mechanical deformation cannot always be recognized.

In all the cases referred to above, the brightness and contrast of the primary colors were adjusted to increase the visibility between light and dark regions. Figure 1 illustrates the result of the overall modifications obtained for each mineral. In a low-contrast image, as indicated in the histograms of primary colors of the original images (Figure 1A, C, and $\mathrm{E}$ ), the number of available intensity pixels occupied only a small part of the distribution range. With the Levenhuk ToupView program's color adjustment curve tool, the dynamic range of pixel values was redistributed such that the lighter pixels became somewhat less clear, whereas the darker pixels became more shaded (Figure 1B, D, and F). Although the improvements were visually perceptible, the histograms clearly illustrate the rearrangement of the luminosity intensity level of each primary color, with the dark tones represented on the left side, the middle tones in the central part, and the light tones on the right side of the diagram. Details of the statistical color distribution values are provided at the bottom. The main advantage of using the curve fitting tool, aside from the possibility of modifying individual channels, is that the corrections can be inserted at any point along the line of the curve.

After this initial phase of treatment, to improve the fidelity of image reproduction and make the result more suitable for subsequent extraction of information, three different manipulation techniques were employed to emphasize the contour lines of the textural features of each mineral. These techniques were applied to the image as a whole to improve the detection of lines and edges of the microstructures, and the results shown in Figure 2 are rather satisfactory. Of course, the visual appearance produced in each case was fairly different. However, in an automated character recognition system, the most appropriate enhancement method is the one that offers the best identification rate of the parts of an object under analysis. From this point of view, the application of the most used techniques, differential direction filtering (embossed surface), negative image, and edge detection, provided better conditions of observation for the analysis and identification of contact types between quartz grains (Figure 2A), myrmekitic intergrowth (Figure 2E), and polysynthetic twinning deformation of plagioclase feldspar (Figure 2I). The embossed appearance is based on the lighting and reflectance properties of the objects, making it possible to emphasize the edges in a specific direction. As shown in Figure 2B, F, and J, the effects of transformation of the intensity values generate more visually attractive areas in the images, and to a certain degree, the images are simplified, increasing the visibility of small parts and other details. In the case of the negative images (Figure $2 \mathrm{C}, \mathrm{G}$ and $\mathrm{L}$ ), also called intensity level slicing, the brightness intensity values are inverted, yielding potentially useful results to identify changes from light to dark regions, in which the textures may be easier to detect. This method has proven to be particularly advantageous for separating regions of the 
dominant phases of two or more minerals that coexist in microstructures of random intergrowth (Figure 2G). The results were equally satisfactory for delineating the narrow bands of deformation of plagioclase feldspar polysynthetic twinning (Figure 2L). In some parts of the image, represented by the lighter regions, the details of the most deformed sector of polysynthetic twinning, such as the maximum curvature of the bent cleavage planes, became more visible. The main utility of the edge detection application is fundamentally to highlight the lines and contours of an object. The method to arrive at this result is essentially comparative and statistical. The program identifies high-contrast areas that can project over a short distance. In practice, the contour of the object of interest will be drawn automatically; therefore, care should be taken only with the sensitivity level to eliminate the effect of noise. Regarding the efficiency of the technique, the most surprising result is exemplified in Figure 2D and H. In both images, for the textural characteristics of the quartz grains and the myrmekitic intergrowth, the contours of the mineralogical phases involved were delineated with high precision. Although the general outline of the plagioclase grain was faithfully reproduced (Figure 2M), the details of the deformation of the polysynthetic twinning lay below the detection limit.
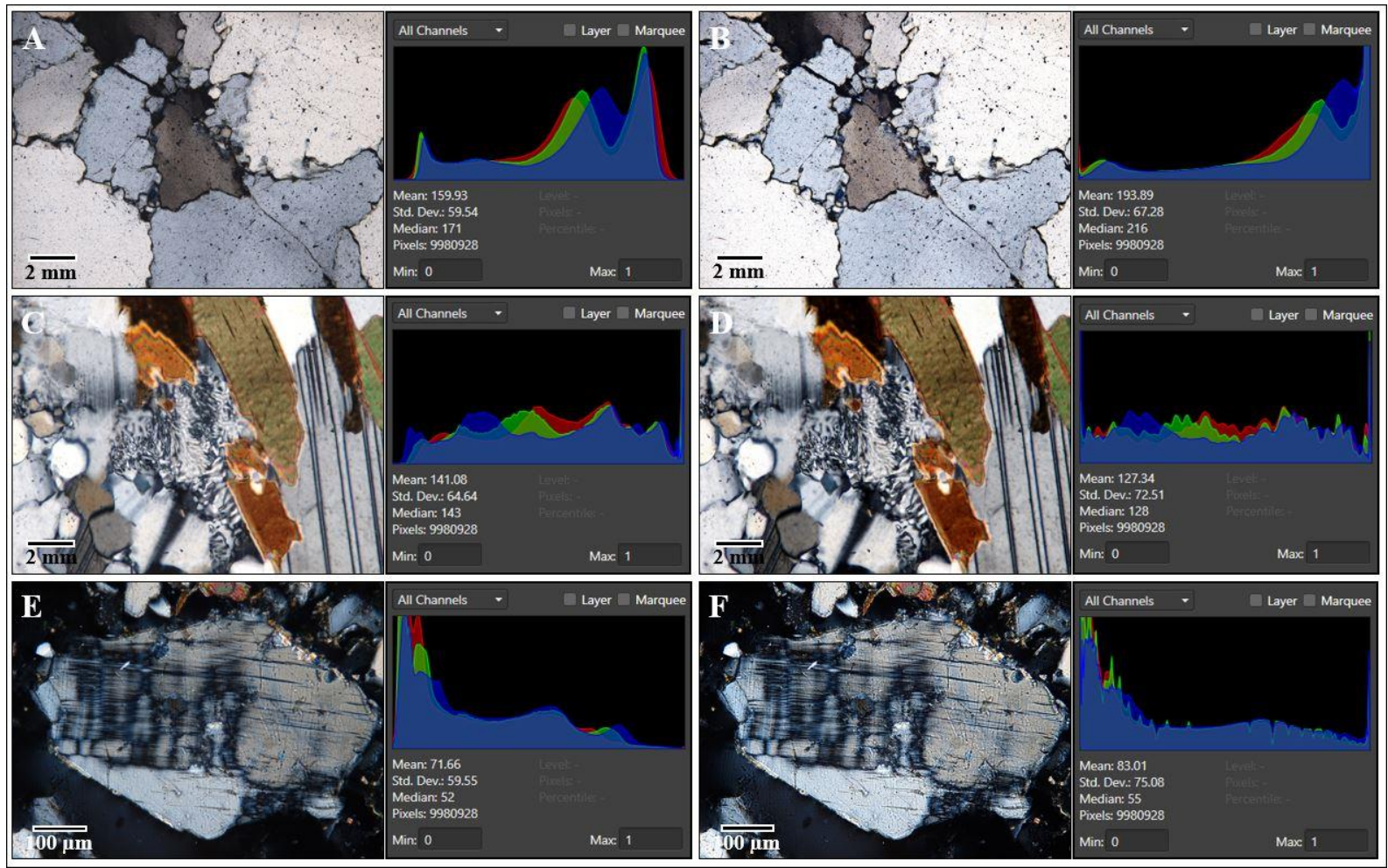

Figure 1. Analytical comparison between the original images (A, C, and E) and those that have been treated (B, D, and F), as well as their corresponding color distribution histograms, for low birefringence minerals. Note that the readjustment applied to the images allowed a considerable gain in contrast, brightness, and sharpness. The observed textural features

are as follows: A-B) boundary migration in quartz grains, C-D) myrmekitic intergrowth, and E-F) deformation of polysynthetic twinning in plagioclase feldspar

\subsection{High Birefringence Minerals}

A particular characteristic of the high birefringence minerals is the strong and bright hues of colors, particularly for the magnesium-iron silicates (Figure 3). Adopting Michael-Lévy's color chart (Michael-Lévy, 1888) as a reference, those minerals occupy the second and third orders in the table, with color ranges varying among violet, blue, green, yellow, orange, and red (Sørensen, 2013). In this study, three common textural features in minerals of basic to ultrabasic magmatic rocks were distinguished. The first concerns olivine, a magnesium-iron silicate and an essential component of the Earth's upper mantle, which generally exhibits a granular habit with intensely fractured edges as a result of friction between grains, causing size reduction in the deformed grains (Mercier \& Nicolas, 1975; Falus, 2004). The second material exhibits a corona texture with several layers of different minerals consisting, from the center outward, of thulite, opaque material, biotite, and aegirine-augite. This mineralogical association is the result of a roughly circular edge dissolution reaction of the partially preserved biotite grain. Different types of corona textures have been studied by several authors. The data point to a model of simultaneous layer growth by diffusion, with the participation of the fluid phase in which mass transfer and precipitation of new minerals occur (Claeson, 1998; Larikova \& Zaraisky, 2009). The following 
example is one of the clearest pieces of evidence of texture disequilibrium. The aegirine-augite phenocrystal displays a coarse spongy/sieve texture in which it is possible to observe several inclusions that may take different shapes, such as circular, elongated, and even irregular shapes. Despite the wide variety of occurrences, including in several other rock-forming minerals, the general consensus seems to be that such textures are strongly related to the dynamic behavior of magma crystallization, influenced by fluctuations of pressure and temperature and sudden change of composition (Nelson \& Montana, 1992; Blundy \& Cashman, 2005; Winter, 2014; Pan et al., 2018).

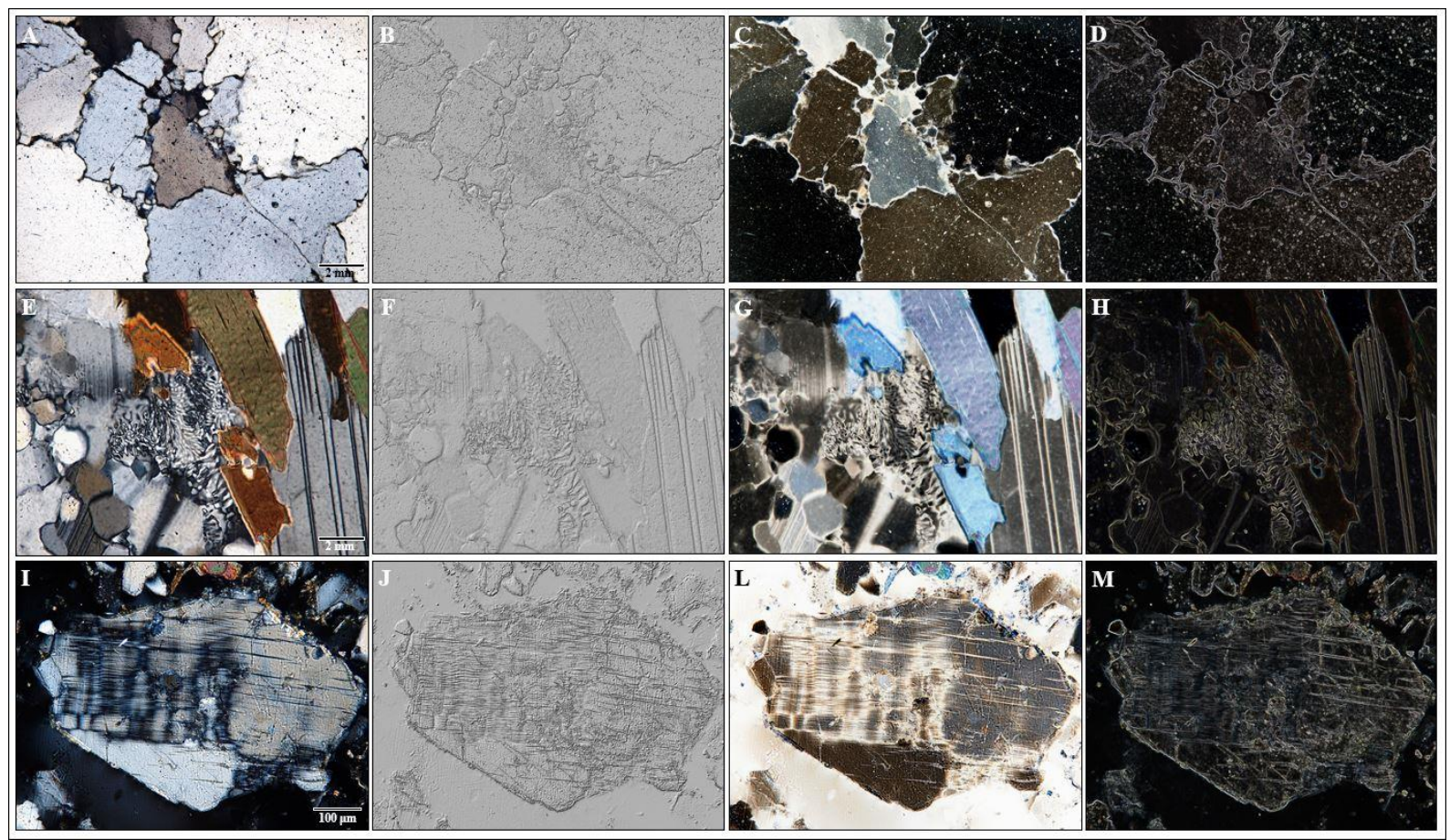

Figure 2. Three representations for low birefringence minerals employing different filters. A) Original image showing the boundary migration in quartz grains. B, C, and D, embossed surface, negative image, and edge detection, respectively. E)

Original image illustrating the myrmekitic intergrowth. F, G, and H, embossed surface, negative image, and edge detection, respectively. I) Original image exhibiting the polysynthetic twinning in plagioclase feldspar. J, L, and M, embossed surface, negative image, and edge detection, respectively

Because of the intense colors of all of these magnesium-iron silicate minerals, it was necessary to make minor adjustments to improve the quality of the brightness and contrast. Shape and size are two very important elements for determining exact boundary locations between objects. Sharp upward or downward variations in brightness and contrast may introduce significant changes in the appearance of the object, interfering directly in the perceptible level of detection for precise contour tracking. To obtain more information about the contours, curved or linear, of the shapes or relationships between the shapes present in the textural features, small modifications of different intervals of brightness and contrast were inserted into the images (Figure 3). The new olivine grains, reduced to minute particles and housed in the interstitial spaces between the margins of the old grains, significantly improved the visual quality, as shown in the central part of Figure 3B. The individual contour lines that demarcate the new small grains around the main grain, forming a narrow irregular band, are the results obtained by interpolation. Gentle reduction in the color intensity favored the identification of the distribution pattern of the mineral grains that made up the corona texture (Figure 3C). This adjustment facilitated the identification of aegirine-augite acicular crystals arranged radially around a mineral aggregate consisting of biotite, opaque, and thulite (Figure 3D). The form and relief of the fine needle-like grains of aegirine-augite crystals became very visible with respect to the adjacent grains of biotite and opaque. The effect of adding brightness and a little contrast are shown in Figure 3F. Improvement in both tonal quality and resolution are easily perceptible in the aegirine-augite phenocrystal. In general, the brightest regions of the host phenocrystal correspond to the spongy domains composed mainly of secondary inclusions of clinopyroxenes, varying from rounded to vermiform in shape, or even resembling small network channels.

Additional treatments were performed to improve the detail level of the records of the visual information of the images. From Figure 4, it is possible to verify that the techniques resulted in visible improvement only for some textures and microstructures. The embossed method was found to be efficient in accurately isolating reduced grain sizes of olivine (Figure 4B). However, for more complex textural features, such as the corona and spongy textures, transformation offered 
limited advantages. In both of these textures, in areas that exhibited different grayscale contrasts (Figure 4F and J), it was difficult to separate the region of intergrowth from the mineralogical phases involved using only the enhancement filters with convolution masks. Adjusting the intensity level slicing to highlight a specific range of intensities and valuing the predominant texture details in the image, as shown in Figure 4C, G, and L, can produce useful results. In the case of an olivine crystal, a darker shade was preferred to highlight the main grain, and a lighter shade outlined the surrounding neoblastic grains (Figure 4C). For the corona texture, which involved the intergrowth of various mineral phases, the use of light shades was more efficient. The simple operation of altering the intensity of the individual pixels of the image provided surprising results in the shape tracing as well as the evident separation of areas with different mineral phases. Thus, four different intergrowth sectors could be recognized (Figure 4G): i) the completely clear areas were domains of opaques, (ii) the slightly bluish regions represented biotite grains, (iii) the prismatic forms with thin bright contours corresponded to the acicular aegirine-augite crystals, and (iv) the small greenish spots were slender thulite grains. The fine details of the spongy texture, in which a large number of inclusions of different shapes and sizes occurred, were revealed only by selective inversion of the intensity level of the image. As shown in Figure 4L, most of the spongy texture features were convincingly recognizable. The domains of the purple-brown-reddish shade represented remnant parts of the host crystal and the light areas, especially those of sinuous shapes, were the inclusions that gave the spongy aspect to the mineral.

Another particularly interesting method for excluding some image elements and highlighting or improving the details is edge detection. The focus of this technique is detecting and tracking down the segment that determines the boundary of the contour between objects, and its precision depends on the degree of local sharp change in edge pixel intensity. Figure $4 \mathrm{D}, \mathrm{H}$, and $\mathrm{M}$ shows the result for each particular case. The very complex nature and the wide variability at the small scale of the textural features are conditioning factors that impose a precision limit for this technique. In this circumstance, this method efficiently isolated the minuscule olivine grains (Figure 4D). However, when the selection is made from a material composed of small particles and broad random shapes, it should be understood that the procedure may not be completely satisfactory. As with the majority of the cases of the corona and spongy textures, the traced results are much less accurate than the results of experiments with other techniques, making it challenging and sometimes even ambiguous to recognize the areas of mineral phase intergrowth (Figure $4 \mathrm{H}$ and $\mathrm{M}$ ). This is to be expected as both of these textures are highly variable in shape and size, and the minimum width of the edges that separate the contact between the phases is quite thin. However, as limited as this procedure may be, there is no doubt about the magnitude and importance that the technique represents as a digital image processing tool.

\section{Final Considerations}

With a wide range of applications, the technique of digital image processing has grown remarkably, and several studies have been conducted on application in the fields of biology, medicine, archeology, and geology. Of course, this paper does not cover all areas related to image digital processing of minerals and rocks; however, the results obtained here represent an important review with respect to the consistency and reliability of some of the available tools that may improve the description and characterization of the textures and microstructures often observed in rocks and minerals examined under a polarized light microscope.

Although the vast majority of optical microscope manufacturers have adhered to the digital world, offering automated microscopes with powerful packages of digital image processing software, these equipments are still unaffordable to many researchers. In this context, it was judged appropriate to conduct research employing low-cost or open-license software that offers a great variety of tools for digital image processing. Likewise, because of the wide variety and complexity of the types of deformation, attention has turned to the textures and microstructures that occur most frequently in minerals with low and high birefringence, and to the specific treatments that may improve interpretation, including image embossing, negative imaging, and edge detection. 


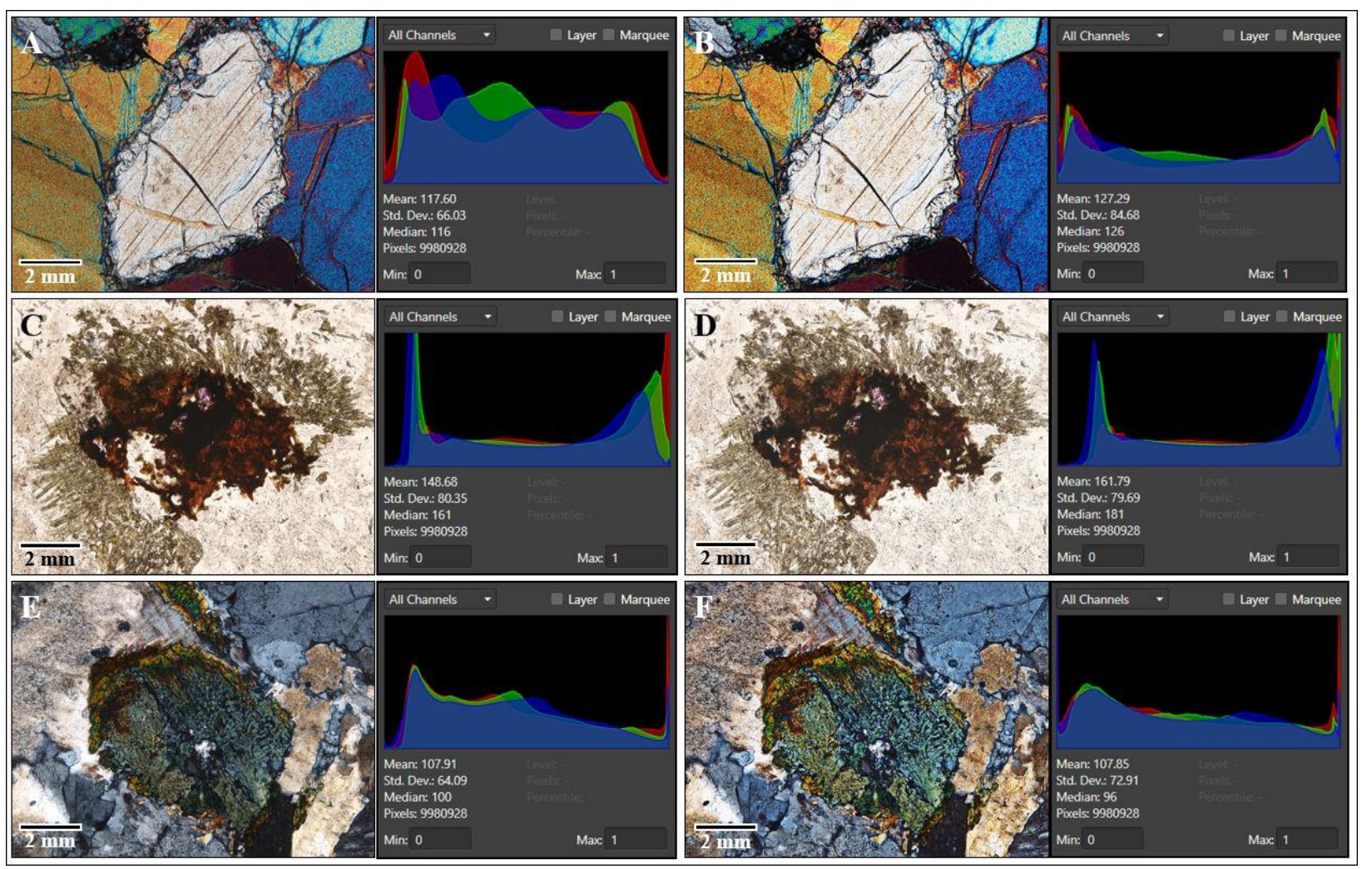

Figure 3. Analytical comparison between the original images (A, C, and E) and those that have been treated (B, D, and F), as well as their corresponding color distribution histograms, for high birefringence minerals. Note that there has been a significant improvement in resolution and color reproduction variations. The observed textural features are as follows: A-B) grain size reduction by friction in deformed olivine crystal, C-D) corona texture with several layers of different minerals (more details in the text) and E-F) coarse spongy/sieve texture in aegirine-augite phenocrystal

The grain boundary migration observed between quartz grains, the myrmekitic intergrowth that brings quartz and feldspar minerals together, and the deformation of fine twinning lamellae present in the plagioclase feldspar crystals became considerably more visually apparent after different processing techniques were applied. The microtexture observed at quartz grain contacts, which involves the growth of new grains, engulfment of minor grains, and boundary line migration (Figure 5), is often attributed to dynamic recrystallization during intense deformation processes (Lloyd, Farmer \& Mainprice, 1997; Bollinger et al., 2019). The details observed in Figure 5B, C, and D, where the recrystallized grains were typically smaller than the primary grains, show lobed contours, almost always at sites of the incipient development of triple junctions. They represent significant evidence that the texture was generated under high-strain deformation, provoking grain-size intragranular reduction and grain boundary migration. Plagioclase feldspar is a mineral sensitive to high-stress conditions (Figure 6), and the microstructures contained therein are commonly evaluated as indicative criteria to infer the deformation mechanism regime (Tullis \& Yund, 1985; Montardi \& Mainprice, 1987). In many ways, the deformation of the polysynthetic twinning of a plagioclase feldspar crystal is more complex than that of quartz grains. According to Marshall and McLaren (1977), those microstructures are formed through a series of mechanical dislocations of the crystal lattice under high strain rates and temperatures, and as a result of such processes, the twinning lamellae are often kinked, bent, or curved or form intertwined networks. This type of deformation, also known as plastic deformation, was well documented in the plagioclase feldspar crystal (Figure 6B, C, and D). The image reveals the stages of the morphological transformation of the polysynthetic twinning, with some truncated lamellae, others only slightly dislocated, a few overlapping, and, in more extreme cases, obliterated. 


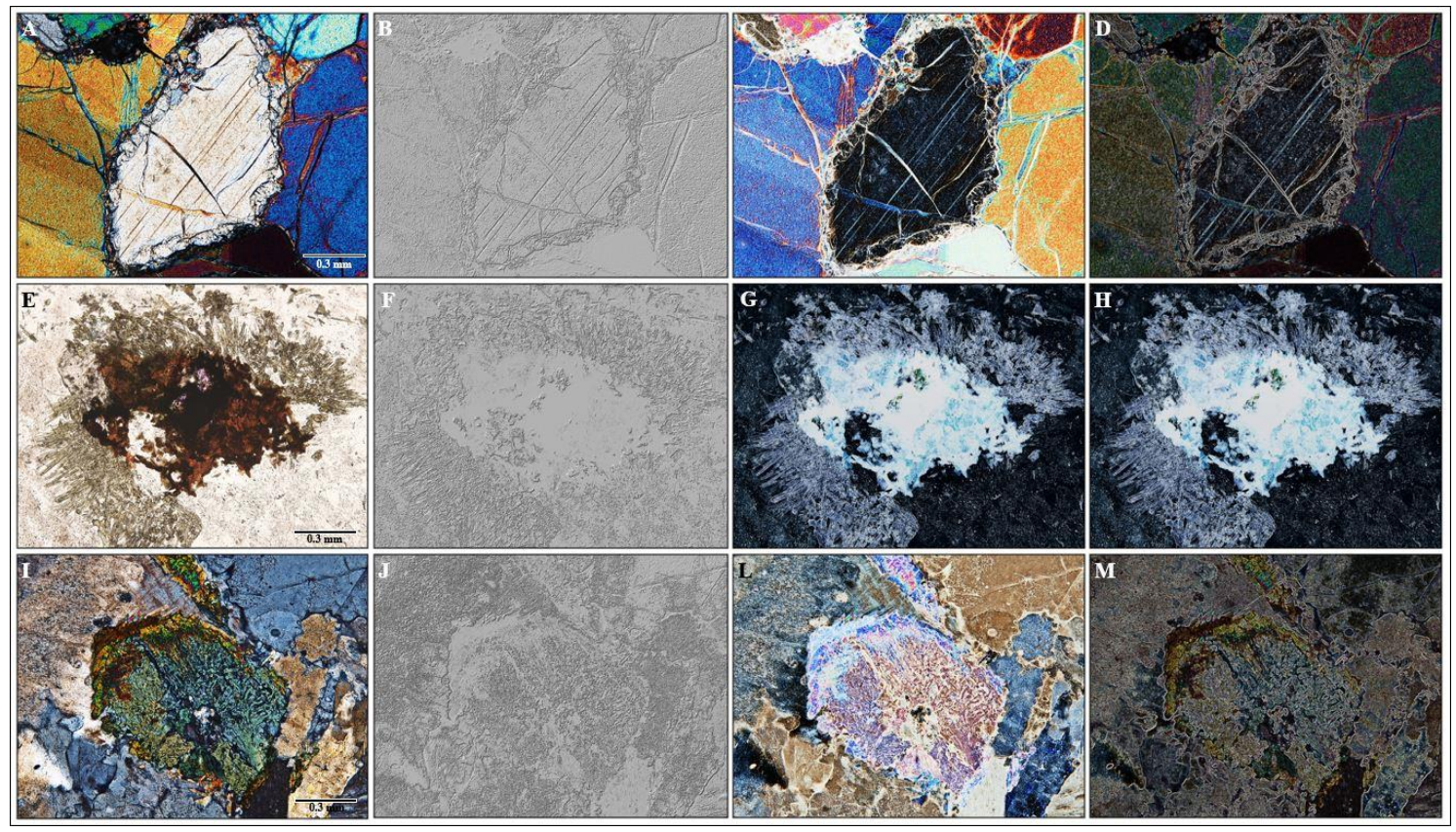

Figure 4. Three representations for high birefringence minerals employing different filters. A) Original image illustrating grain size reduction in olivine crystal. B, C, and D, embossed surface, negative image, and edge detection, respectively. E) Original image showing corona texture with several layers of different minerals. F, G, and H, embossed surface, negative image, and edge detection, respectively. I) Original image giving an example of coarse spongy/sieve texture in aegirine-augite phenocrystal. J, L, and M, embossed surface, negative image, and edge detection, respectively

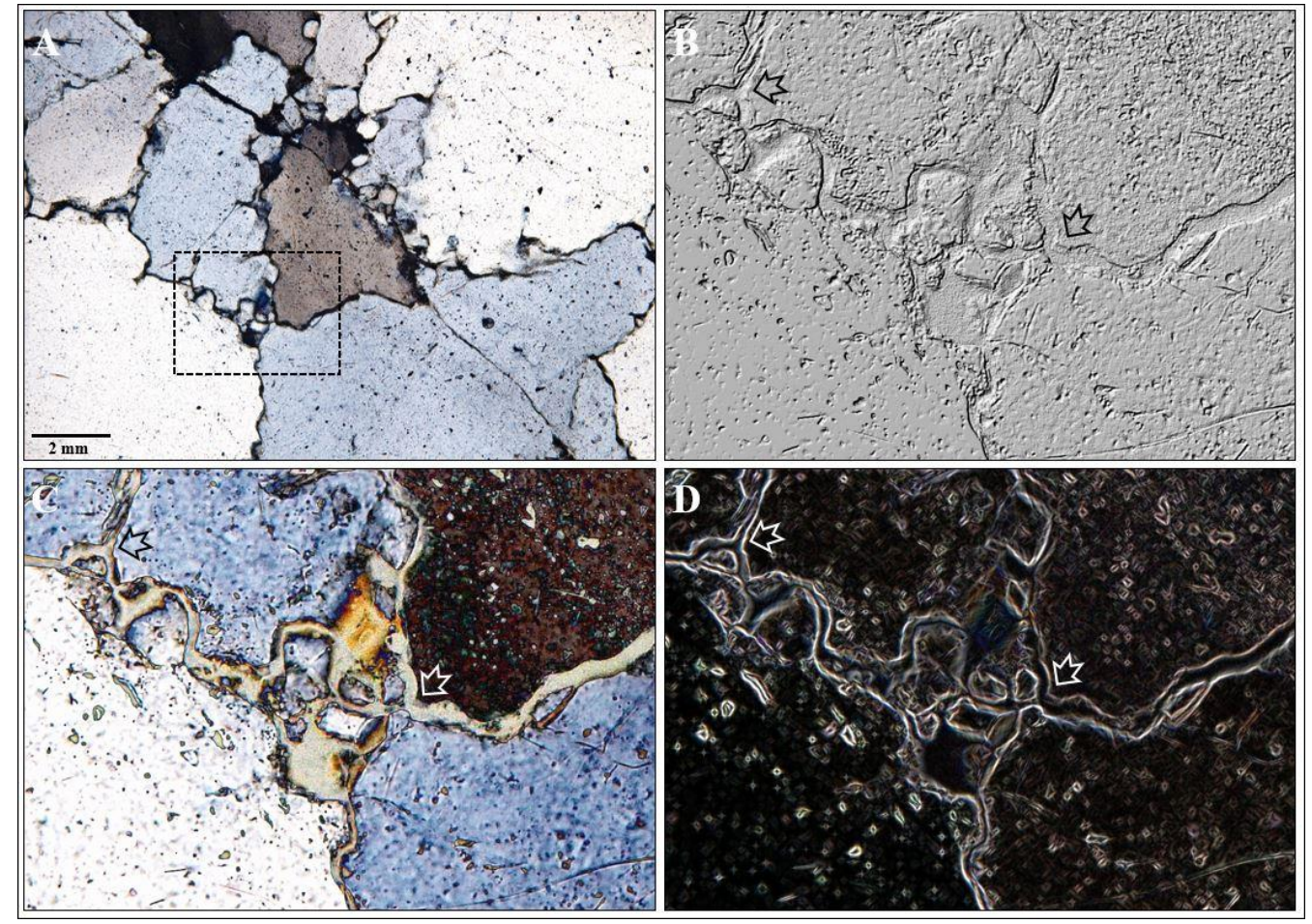

Figure 5. Detailed images of the boundary migration feature in quartz grains (A) based on three different operations of transformation: embossed surface (B), negative image (C) and edge detection (D). The arrows in the images indicate the most obvious places of the curvilinear limits of grain boundary migration, the engulfment of smaller grains, and the incipient formation of the triple joints. The dotted rectangular shape in A represents the area that has been enlarged 5x in B, $\mathrm{C}$, and D

Although different processes may take over during the development of the microtextures in magnesium-iron silicate 
minerals, it is beyond the scope of this paper to debate the petrogenetic models. There are numerous studies in the literature to provide a comprehensive understanding of the various aspects of petrogenesis. However, it is important to remember that good interpretation of texture depends on the description and precise characterization of the mineralogical phases. From this point of view, the approach should consider the performance of a combination of digital image processing techniques to allow better morphological definition of intergrowth texture based on sharp changes in intensity. Replacement textures, reaction rims, and intergrowth textures occur when a mineral or mineral aggregate presents the outer crystalline form of a different preexisting mineral, or when the relation of the contact between two different minerals suggests the generation of one at the expense of the other (Clarke \& Powell, 1991; Passchier \& Trouw, 2005; Vernon, 2018). To elucidate these aspects, two different situations of partial phenocrystal reabsorption, resulting in the formation of a corona texture (Figure 7) or in a typical vermiform intergrowth called a spongy texture (Figure 8), are described as follows. Although in general terms, both textures may contain small scattered grains of the original mineral with a similar range of optical properties, the technical details and approach to the problem require different methods. The particularities of a single rim corona texture are documented in Figure 7B, C, and D. The formation of new minerals, which are invariably heterogeneous in terms of crystal shape and size, can be observed in many parts of the texture. Special reference may be made to the thin radially arranged acicular aegirine-augite crystals around the opaque and biotite xenomorphic grains. In volcanic rocks, it is relatively common to observe phenocrystals with reaction edges or partially resorbed grains, forming a symplectic intergrowth complex commonly referred to as spongy/sieve texture (Renjith, 2014; Pan et al., 2018). The inclusions that form the spongy texture are morphologically amoeboidal, of roughly uniform size, sometimes isolated or interconnected, and randomly distributed in the host crystal (Figure 8B, C and D). These characteristics strongly indicate that the spongy domain phase was generated by partial fusion of the primary aegirine-augite phenocryst during a decompression process. The boundaries between the amoeboidal inclusions and the remnant grain of aegirine-augite are noticeable in images to which the three image processing techniques were applied.
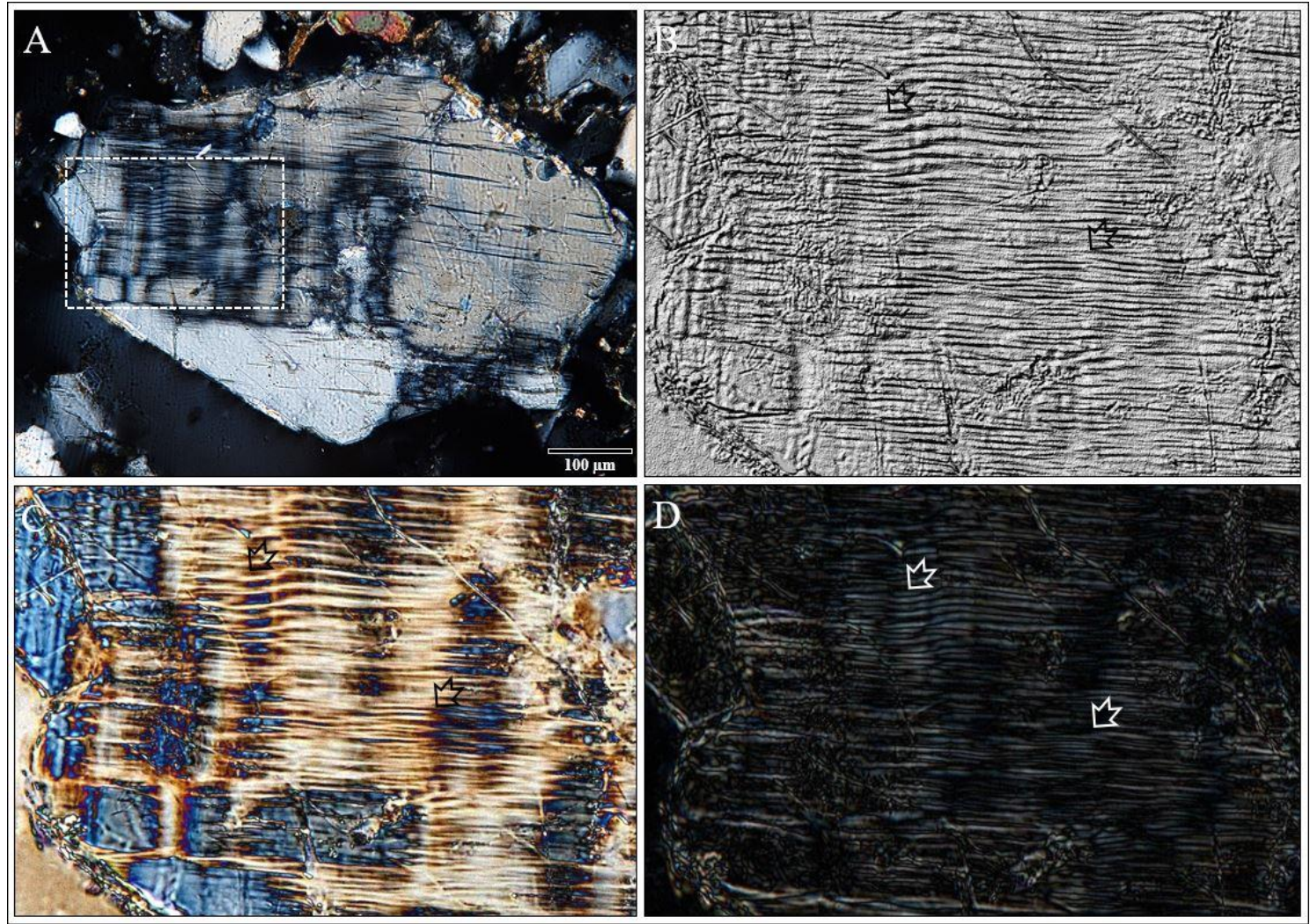

Figure 6. Detailed images of the deformation of polysynthetic twinning in plagioclase feldspar crystal (A) based on three different operations of transformation: embossed surface (B), negative image (C) and edge detection (D). The arrows in the images indicate the most intense deformation sites of the polysynthetic twinning. The dotted rectangular shape in $\mathrm{A}$ represents the area that has been enlarged $5 \mathrm{x}$ in $\mathrm{B}, \mathrm{C}$, and $\mathrm{D}$

Most of the digital image processing techniques employed were efficient to improve the visualization of the shape and size relationships of the investigated textures and microstructures. In general, processing relies on adjusting the intensity values to effectively increase the overall contrast of the image elements. In the field of polarized light microscopy, in 
addition to the remarkable efficiency for the characterization of textures, these techniques can also be used in several other areas of geosciences, such as in the identification of microdeformation resulting from tectonic activity, evaluation of microsegregations commonly found in sedimentary and metamorphic rocks, and petrofabric analysis for petroleum geology. Digital image processing is also a powerful tool for other less conventional areas of the geosciences where petrographic analysis is widely used, such as in archeology, concrete petrography, and materials science.

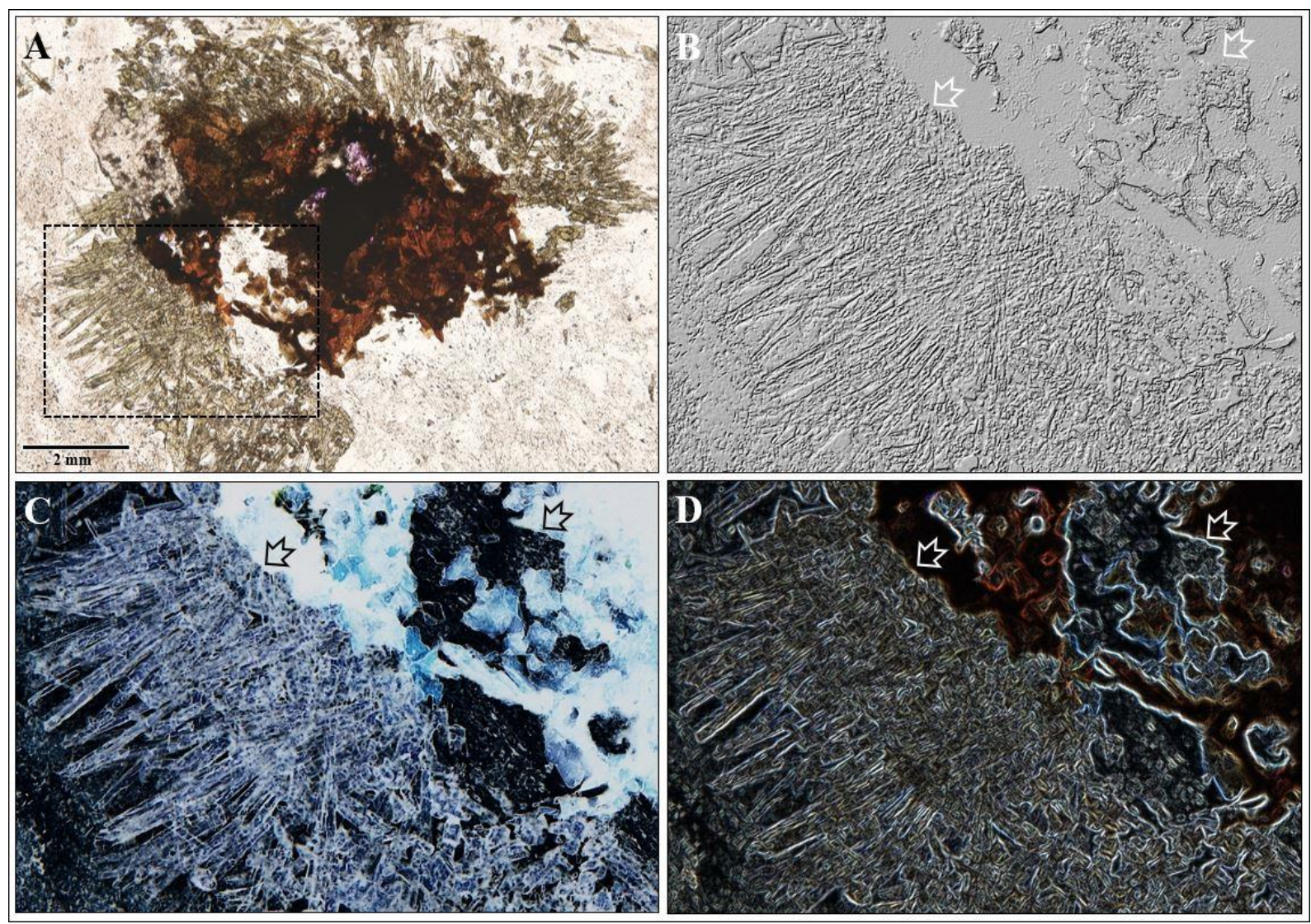

Figure 7. Detailed images of the corona texture with several layers of distinctive minerals (A) based on three different operations of transformation: embossed surface (B), negative image (C) and edge detection (D). The arrows in the images indicate the limits of evident separation between the mineral phases, highlighting the aegirine-augite acicular crystals. The dotted rectangular shape in A represents the area that has been enlarged $5 \mathrm{x}$ in $\mathrm{B}, \mathrm{C}$, and $\mathrm{D}$ 


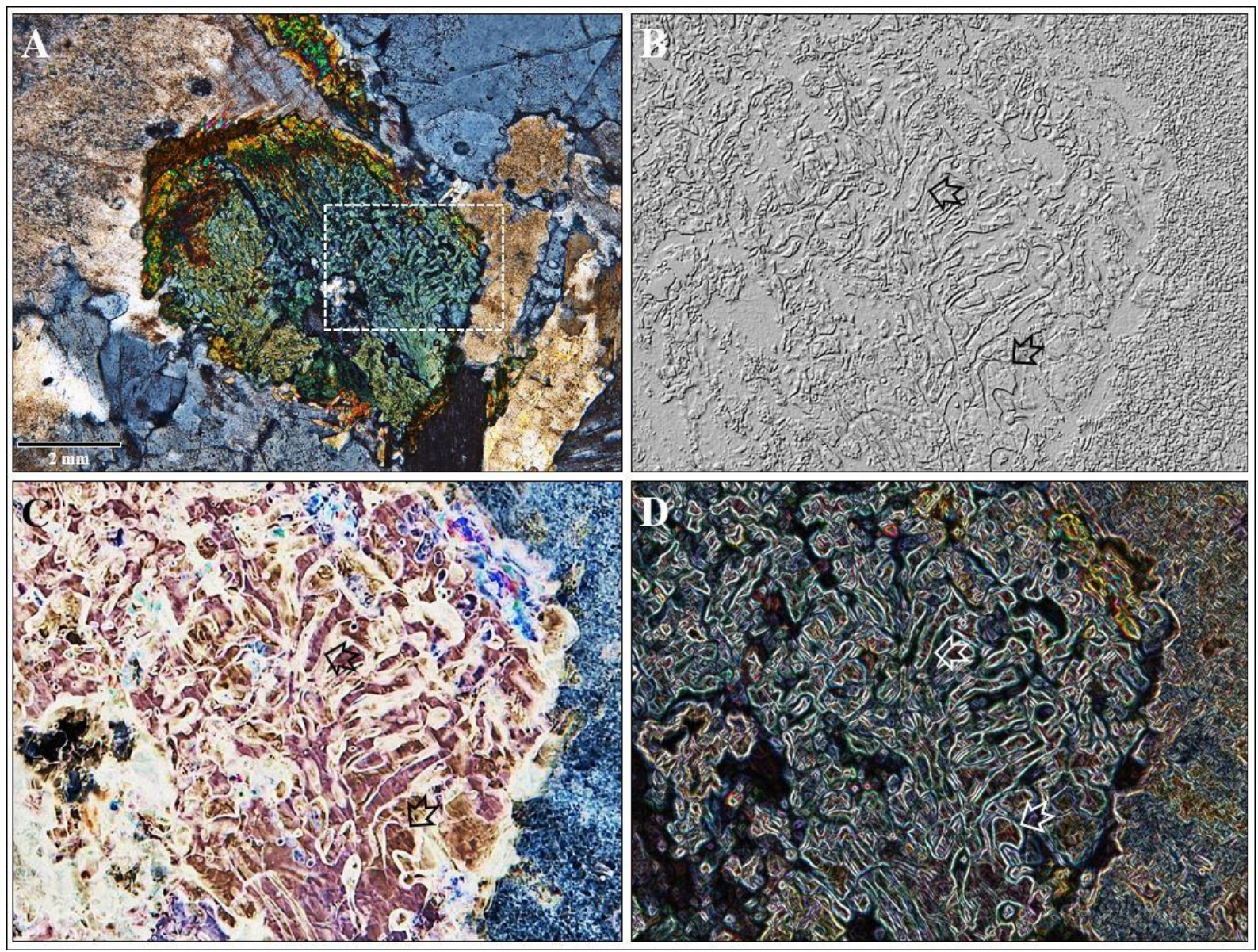

Figure 8. Detailed images of the spongy/sieve texture with several inclusions randomly distributed in the host crystal (A) based on three different operations of transformation: embossed surface (B), negative image (C) and edge detection (D).

The arrows indicate the most eloquent areas to observe part of the original material remaining of the aegirine-augite phenocrystal which was partially reabsorbed. The dotted rectangular shape in A represents the area that has been enlarged $5 \mathrm{x}$ in $\mathrm{B}, \mathrm{C}$, and $\mathrm{D}$

\section{Acknowledgments}

We received help from a large number of people during the preparation of this paper. We are grateful to the colleagues of both institutions, EACH-USP and IG-SMA, for their help and support. B.M. Dias thanks the PUB-USP agency for granting the scholarship. This study has been supported by the Fapesp agency (Procs. 2011/50987-0, 2012/50042-9, 2016/23399-4).

\section{References}

Barnes, J. W., \& Lisle, R. J. (2004). Basic geological mapping. Ontario, Canada: John Wiley \& Sons.

Berryman, J. G., \& Blais, S. C. (1986). Use of digital image analysis to estimate fluid permeability of porous materials: Application of two-point correlation function. Journal of Applied Physics, 60(6), 1930-1938. https://doi.org/10.1063/1.337245

Blundy, J., \& Cashman, K. (2005). Rapid decompression-driven crystallization recorded by melt inclusions from Mount St. Helens Volcano. Geology, 33(10), 793-796. https://doi.org/10.1130/G21668.1

Bollinger, C., Nzognag, B. C., Mussi, A., Bouquerel, J., Molodov, D. A., \& Cordier, P. (2019). Microstructural evidence for grain boundary migration and dynamic recrystallization in experimentally deformed forsterite aggregates. Minerals, 9(1), 1-17. https://doi.org/10.3390/min9010017

Broche, J., Casanova, R., \& Loup, G. (1977). Atlas des minéraux en grains: identification par photographies en couleurs. France, Société pour le développement minier de la Côte d'Ivoire.

Chaki, N., Shaikh, S. H., \& Saeed, K. (2014). Exploring image binarization techniques. New York, USA: Springer Inc. https://doi.org/10.1007/978-81-322-1907-1 
Claeson, D. T. (1998) Coronas, reaction rims, symplectites and emplacement depth of the Rymmen gabbro, Transscandinavian Igneous Belt, southern Sweden. Mineralogical Magazine, 62(6), 743-757. https://doi.org/10.1180/002646198548133

Clarke, G. L., \& Powell, R. (1991). Decompressional coronas and symplectites in granulites of the Musgrave Complex, central Australia. Journal of Metamorphic Geology, 9, 441-450. https://doi.org/10.1111/j.1525-1314.1991.tb00538.x

Falus, G. (2004). Microstructural analysis of upper mantle peridotites: theirs application in understanding mantle process during deformation of the intra-carpathian basin system (Unpublished doctoral dissertation). Eotvos University, Budapest.

Fleischer, M., Wilcos, R. E., \& Matzko, J. J. (1934) Microscopic determination of the nonopaques minerals. Geological Survey Bulletin, 1627, 453.

Gribble, C. D., \& Hall, J. A. (1992). Optical mineralogy: principles and practice. New York, USA: Chapman \& Hall. https://doi.org/10.1007/978-1-4615-9692-9

Hagara, M., \& Kubinec, P. (2018). About edge detection in digital images. Radioengineering, 27, 919-929. https://doi.org/10.13164/re.2018.0919

Larikova, T. L., \& Zaraisky, G. P. (2009). Experimental modelling of corona textures. Journal Metamorphic Geology, 27, 139-151. https://doi.org/10.1111/j.1525-1314.2008.00809.x

Lloyd, G. E., Farmer, A. B., \& Mainprice, D. (1997). Misorientation analysis and orientation of subgrain and grain boundaries. Tectonophysics, 279, 55-78. https://doi.org/10.1016/S0040-1951(97)00115-7

MacKenzie, W. S., Donaldson, C. H., \& Guilford, C. (1982). Atlas of igneous rocks and their textures. New York, USA: John Wiley \& Sons, Inc.

Mange, M. A., \& Maure, H. F. W. (1992). Have minerals in colour. London, UK: Chapman \& Hall. https://doi.org/10.1007/978-94-011-2308-2

Marshall, D. B., \& McLaren, A. C. (1977). Deformation mechanisms in experimentally deformed plagioclase feldspars. Physics and Chemistry Minerals, 1, 351-370. https://doi.org/10.1007/BF00308845

Mercier, J. C. C., \& Nicolas, A. (1975). Textures and fabrics of upper-mantle peridotites as illustrated by xenoliths from basalts. Journal of Petrology, 16(2), 454-487. https://doi.org/10.1093/petrology/16.2.454

Michael-Lévy, A. (1888). Les minéraux des roches. Application des méthodes minéralogiques et chimiques a leur étude microscopique. France, Paris: Librairie Polytechnique, Baudry et Compagnie.

Montardi, Y., \& Mainprice, D. A. (1987). Transmission electron microscopic study of the natural plastic deformation of plagioclase (An68-70). Bulletin of Mineralogy, 110, 1-14. https://doi.org/10.3406/bulmi.1987.8022

Nelson, S. T., \& Montana, A. (1992). Sieve-textured plagioclase in volcanic rocks produced by rapid decompression. American Mineralogist, 77, 1242-1249.

Nuttall, R. H. (1981). The first microscope of Henry Clifton Sorby. Technology and Culture, 22, 275-280. https://doi.org/10.2307/3104901

Onajite, E. (2014). Seismic data analysis techniques in hydrocarbon exploration. Miami, USA: Elsevier Inc.

Pakhira, M. K. (2011). Digital image processing and pattern recognition. New Delhi; India: PHI Learning Pvt. Ltd.

Pan, S., Zheng, J., Yin, Z., Griffin, W. L., Xia, M., Lin, A., \& Zhang, H. (2018). Spongy texture in mantle clinopyroxene records decompression-induced melting. Lithos, 320-321, 144-154. https://doi.org/10.1016/j.lithos.2018.08.035

Passchier, C. W., \& Trouw, R. A. J. (2005) Microtectonics. New York, USA: Springer-Verlag.

Petru, M., \& Bosdogianni, P. (1999). Image processing: the fundamentals. Ontario, Canada: John Wiley \& Sons Ltd. https://doi.org/10.1002/0470841907

Pratt, W. K. (2007). Digital image processing. New Jersey, USA: John Wiley \& Sons, Inc. https://doi.org/10.1002/0470097434

Renjith, M. L. (2014). Micro-textures in plagioclase from 1994e1995 eruption, Barren Island Volcano: Evidence of dynamic magma plumbing system in the Andaman subduction zone. Geoscience Frontiers, 5, 113-126. https://doi.org/10.1016/j.gsf.2013.03.006

Russ, J. C. (2011). The image processing handbook. New York, USA: Taylor \& Francis Group. 
Sørensen, B. E. (2013). A revised Michel-Lévy interference colour chart based on first-principles calculations. European Journal Mineralogy, 25, 5-10. https://doi.org/10.1127/0935-1221/2013/0025-2252

Spencer, E. W. (2018). Geologic maps: a practical guide to preparation and interpretation. Long Grove, Illinois, USA: Waveland Press Inc.

Stoiber, R. E., \& Stearns, A. M. (1994). Crystal identification with the polarizing microscope. New York, USA: Chapman \& Hall. https://doi.org/10.1007/978-1-4615-2387-1

Tullis, J., \& Yund, R. (1985). Dynamic recrystallisation of feldspar mechanism for ductile shear zone formation. Geology, 13, 283-241. https://doi.org/10.1130/0091-7613(1985)13<238:DROFAM>2.0.CO;2

Umbaugh, S. E. (2018). Digital image processing and analysis: human and computer vision applications with CVIPtools. New York, USA: Taylor \& Francis Group.

Vernon, R. H. (2018). A practical guide to rocks microstructure. Cambridge, UK: Cambridge University Press. https://doi.org/10.1017/9781108654609

Winter, J. D. (2014). Principles of igneous and metamorphic petrology. Edinburgh, UK: Pearson Education Limited.

\section{Copyrights}

Copyright for this article is retained by the author(s), with first publication rights granted to the journal.

This is an open-access article distributed under the terms and conditions of the Creative Commons Attribution license (http://creativecommons.org/licenses/by/4.0/). 